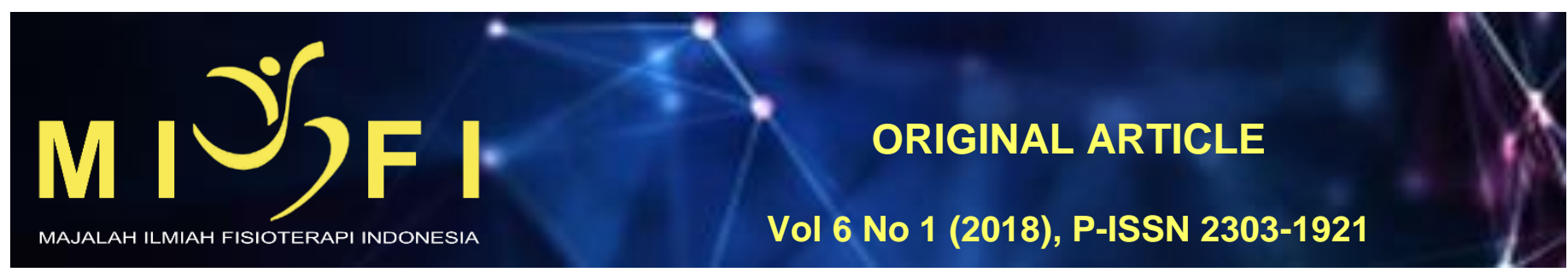

\author{
INTERVENSI FOUR SQUARE STEP LEBIH EFEKTIF \\ DALAM MENINGKATKAN KESEIMBANGAN DINAMIS \\ DARIPADA BALANCE STRATEGY EXERCISE PADA LANSIA \\ DI KELURAHAN TONJA, DENPASAR TIMUR, BALI
}

Putu Ayunia Laksmita1, Ni Luh Nopi Andayani ${ }^{2}$, I Gusti Ayu Artini ${ }^{3}$

1,2 Program Studi Fisioterapi Fakultas Kedokteran Universitas Udayana, Bali

${ }^{3}$ Bagian Farmakologi Fakultas Kedokteran Universitas Udayana, Bali ayunialaksmita@gmail.com

\begin{abstract}
ABSTRAK
Keseimbangan dinamis ialah kemampuan seseorang untuk mempertahankan posisi tubuh saat bergerak. Tujuan penelitian ini untuk mengetahui efek intervensi four square step lebih efektif dalam meningkatkan keseimbangan dinamis daripada balance strategy exercise. Penelitian menggunakan rancangan Pre and Post Test Two Group Design. Berdasarkan hasil penelitian menunjukkan adanya peningkatan keseimbangan dinamis pada kelompok perlakuan 1 sebesar 3,222 dan kelompok perlakuan 2 sebesar 4,444. Hasil uji Paired Sample T-test didapatkan perbedaan yang signifikan yaitu, $\mathrm{p}=0,000$ pada kelompok perlakuan 1 dan kelompok perlakuan 2. Uji selisih Mann-Whitney U-test menunjukkan ada perbedaan yang bermakna antara kelompok perlakuan 1 dan kelompok perlakuan yaitu, $p=0,001$. Disimpulkan bahwa intervensi four square step lebih efektif dalam meningkatkan keseimbangan dinamis daripada balance strategy exercise pada lansia.
\end{abstract}

Kata kunci : keseimbangan dinamis, balance strategy exercise, four square step.

\title{
THE FOUR SQUARE STEP INTERVENTION IS MORE EFFECTIVE IN IMPROVING THE DYNAMIC BALANCE RATHER THAN BALANCE STRATEGY EXERCISE IN THE ELDERLY OF VILLAGE OF TONJA, EASTERN DENPASAR, BALI
}

\begin{abstract}
Dynamic balance is the ability to maintain body position while moving. The purpose of this study was to determine the effect of four square step interventions that is more effective in improving the dynamic balance rather than balance strategy exercise. This research is an experimental design using Pre and Post Test of Two Group Design. The results showed an increase in dynamic balance in the treatment of group 1 of 3.222 and there was an increase of 4,444 in the treatment group 2. Results of paired samples t-test found a significant difference with $p=0.000(p<0.05)$ in the treatment group 1 and $p=0.000(p<0.05)$ in the treatment of group 2. The differential test of Mann Whitney u test showed no significant difference between the treatment group 1 and treatment group 2 in which $p=0.01(p<0.05)$. It can be concluded that the four square step interventions is more effective in improving the dynamic balance rather than the balance strategy exercise in the elderly.

Keywords: dynamic balance, balance exercise strategy, four square step
\end{abstract}




\section{PENDAHULUAN}

Lansia ialah keadaan yang ditandai oleh kegagalannya seseorang dalam mempertahankan posisi terhadap kondisi stress fisiologis. ${ }^{1}$ Pada era ini insiden jatuh umumnya sering terjadi pada lansia, seiring bertambahnya usia angka insiden jatuh pada lansia yang berumur 65 tahun atu lebih semakin meningkat. ${ }^{2}$ Jatuh dapat diartikan sebagai suatu keadaan yang membuat seseorang tiba-tiba berada di posisi yang berbeda bahkan lebih rendah dari posisi awal. ${ }^{3}$

Survey yang dilakukan oleh Tinneti di masyarakat AS, terdapat 30\% lanjut usia yang berumur 65 tahun bahkan lebih mengalami insiden jatuh setiap tahunnya. Setengah dari angka tersebut mengalami kejadian jatuh berulang ${ }^{4}$. Penyebab utama lansia sering jatuh adalah keseimbangan yang kurang atau tidak baik. Terjadinya penurunan keseimbangan dan gangguan berjalan pada lanjut usia sebagai akibat menurunnya kekuatan otot atau penyakit penyerta yang sedang di derita lansia. Menurunnya keseimbangan bisa diperbaiki dengan berbagai latihan keseimbangan. Latihan-latihan pada lansia yang meliputi komponen-komponen keseimbangan akan menurunkan insiden jatuh pada lansia 5 .

Keseimbangan adalah kemampuan tubuh dalam memelihara pusat massa tubuh dengan menjaga batasan stabilitas yang ditentukan oleh pusat dasar penyangga. Keseimbangan terdiri dari dua macam yaitu keseimbangan statis dan keseimbangan dinamis yang dipengaruhi oleh faktor-faktor sistem sensoris, vestibuler, proprioseptif dan muskuloskeletal. Keseimbangan dinamis ialah keadaan atau kemampuan dalam mempertahankan posisi tubuh saat bergerak atau Center of Gravity (COG) selalu berubah seperti berjalan. ${ }^{6}$ Dalam mempertahankan keseimbangan diperlukan komponen-komponen untuk mengontrol antara lain, sistem sensorik meliputi: visual, vestibular, proprioceptive, sistem sensorik, sistem motorik meliputi: muskuloskeletal, sendi jaringan lunak yang keseluruhan kerjanya diatur oleh otak terhadap pengaruh internal dan eksternal tubuh. Keseimbangan sangat penting dalam menjaga posisi tubuh saat diam atau pun dalam posisi bergerak. Berbagai gerakan pada setiap segmen tubuh perlu di kontrol oleh sistem keseimbangan yang didukung oleh sistem muskuloskeletal dan bidang tumpu. ${ }^{8}$

Ada begitu banyak metode untuk meningkatkan keseimbangan dinamis pada lansia dalam mengatasi dan mencegah terjadinya gangguan keseimbangan, salah satunya adalah Balance Strategy Exercise. Balance strategy exercise merupakan sekumpulan latihan yang digunakan untuk meningkatkan keseimbangan pada lansia dengan teknik penguatan dan peregangan pada otot. ${ }^{8}$

Balance strategy exercise dibagi menjadi tiga gerakan, yaitu: ankle strategy, hip strategy, dan stepping strategy. Ankle strategy exercise dapat dikendalikan oleh fulkrum-fulkrum sendi melalui kontraksi gerakan plantarflexor dan dorsiflexor otot untuk menggerakkan pusat massa tubuh. Aktivasi awal dorsal ankle diikuti oleh aktivasi otot paha dan otot trunk. Hip strategy exercise dikontrol oleh sendi pinggul melalui kontraksi gerakan fleksor hip dan trunkus. Sedangkan gerakan stepping strategy exercise merupakan gerakan melangkah ke arah depan atau ke arah belakang dimana yang bertujuan dalam mempertahankan bidang tumpu agar pusat massa tubuh tetap berada di dalam bidang tumpu. ${ }^{2}$ Gerakan-gerakan yang terdapat pada gerakan balance strategy exercise dapat meningkatkan kekuatan otot anggota gerak bawah dan menjaga sendi-sendi, postur tubuh tetap baik. Selain itu, balance strategy exercise juga dapat menyebabkan otot berkontraksi dan selanjutnya dapat menimbulkan serat otot meningkat sehingga dapat meningkatkan kekuatan otot serta keseimbangan pada lansia. ${ }^{4}$

Latihan balance exercise dalam hal ini balance strategy exercise merupakan serangkaian gerakan yang dilakukan untuk meningkatkan stabilitas tubuh dengan cara memperbaiki kekuatan otot-otot pada ekstremitas bawah sehingga meningkatkan keseimbangan postural pada lansia dan mencegah timbulnya jatuh. ${ }^{9}$ Penelitian lain menyebutkan intervensi four square step memiliki pengaruh dalam meningkatkan keseimbangan dinamis pada lansia yang disebabkan karena aktivitas fisik yang terencana. ${ }^{10}$

Intervensi four square step dapat melatih otot-otot, persendian, dan melatih koordinasi sistem visual, vestibuler terhadap lingkungan. Pada intervensi four square step memadukan gerakan aktivitas fisik antara gerakan melangkah kearah depan (maju), melangkah kearah belakang (mundur), melangkah ke samping kiri dan melangkah ke kanan. ${ }^{11}$ Penelitian yang berjudul "The realibility and validity of the Four Square Step test for people with balance dificits secondary to a vestibular disorder" yang dilakukan oleh Whitney SL menyebutkan bahwa four square step merupakan sebuah tes klinis yang sangat valid, terpercaya dan dapat diandalkan. ${ }^{12}$ Kedua jenis metode latihan yang berbeda ini efektif dalam meningkatkan keseimbangan dinamis pada lansia. Penelitian yang membandingkan perbedaan efektifitas kedua metode yang berbeda tersebut belum pernah dilakukan di Bali.

\section{BAHAN DAN METODE}

Penelitian ini menggunakan pre test and post test two group design, sampel dibagi menjadi dua kelompok berbeda dengan teknik pengambilan sampel yaitu purposive sampling. Lokasi penelitian ini dilakukan di Kelurahan Tonja Denpasar Timur, Bali pada bulan Februari-Maret 2016.

Populasi target penelitian adalah semua lanjut usia di Kota Denpasar. Populasi terjangkau penelitian adalah semua lanjut usia di Kelurahan Tonja, Denpasar Timur sebanyak 18 orang. Jumlah besar sampel ditentukan berdasarkan hasil studi pendahuluan yang didapatkan rerata Berg Balance Scale (BBS) sebesar 44,29 dan diharapkan peningkatan lebih dari $20 \%$ dari penelitian sebelumnya, sehingga menjadi 53,14 . Jumlah sampel pada penelitian ini ditentukan dengan rumus Pocock. Dari perhitungan rumus Pocock didapatkan 7 sampel. Mengantisipasi adanya sampel keluar, maka jumlah sampel ditambah 20\% menjadi sejumlah 9 sampel, sehingga terdapat 9 sampel pada setiap kelompok. Maka jumlah sampel seluruhnya adalah 18 responden.

Sampel penelitian ini didapat dari populasi penelitian dan setelah memenuhi kriteria inklusi. Kriteria inklusi meliputi: a) Lansia yang berusia 60-74 tahun b) Lansia dengan nilai BBS sebesar 41-56 c) Lansia dengan IMT normal sampai overweight. Kriteria eksklusi meliputi: a)Lansia dengan gangguan berjalan b)Lansia dengan adanya tremor c)Lansia dengan fraktur ekstremitas bawah. Kriteria sampel drop out meliputi: a)Sampel mengundurkan diri b)Kondisi sampel tiba-tiba memburuk setelah diberikan latihan c)Sampel yang tidak kooperatif mengikuti penelitian. 
Alat ukur yang digunakan untuk mengukur keseimbangan dinamis adalah Berg Balance Scale dengan 14 item pengukuran dari skala 0 sampai 4. Skor maksimum untuk pengukuran BBS adalah 56. Berg Balance Scale dinilai sebagai prediktor yang paling efektif untuk gangguan keseimbangan serta sudah beberapa kali divalidasi. ${ }^{14} \mathrm{Lansia}$ yang memiliki skor BBS sebesar 50 cenderung memiliki resiko jatuh sebesar $10 \%$ dan apabila skor BBS sebesar 38 atau kurang maka lansia memiliki resiko jatuh sebesar $90 \% .^{15}$

HASIL

Tabel 1. Hasil Distribusi Data Sampel Berdasarkan Jenis Kelamin dan Usia

\begin{tabular}{|c|c|c|c|c|}
\hline Karakteristik & n & Balance Strategy Exercise (\%) & $\mathbf{n}$ & Four Square Step (\%) \\
\hline \multicolumn{5}{|c|}{ Jenis Kelamin (\%) } \\
\hline Lelaki & 3 & 33,3 & 2 & 22,2 \\
\hline Perempuan & 6 & 66,7 & 7 & 77,8 \\
\hline \multicolumn{5}{|c|}{ Usia } \\
\hline Rerata $\pm($ SB) & & $66,11 \pm(6,287)$ & & $69,33 \pm(2,915)$ \\
\hline
\end{tabular}

Tabel 1 menunjukan distribusi data pada kelompok balance strategy exercise (KP 1) subjek yang berjenis kelamin lelaki berjumlah 3 orang (33,3\%) dan perempuan berjumlah 6 orang $(66,7 \%)$. Kelompok four square step (KP 2) subjek yang berjenis kelamin lelaki berjumlah 2 orang $(22,2 \%)$ dan perempuan berjumlah 7 orang $(77,8 \%)$, sehingga jumlah keseluruhan sampel pada kelompok balance strategy exercise (KP 1) dan four square step (KP 2) berjumlah 18 orang. Subjek penelitian pada kelompok balance strategy exercise (KP 1) memiliki rerata usia 66,11 (SB 6,287). Pada kelompok four square step (KP 2) memiliki rerata usia 69,33 (SB 2,915).

Tabel 2. Hasil Uji Normalitas dan Homogenitas Peningkatan Keseimbangan Dinamis Sebelum dan Sesudah Intervensi

\begin{tabular}{|c|c|c|c|c|c|}
\hline \multirow{3}{*}{ Kelompok Data } & \multicolumn{4}{|c|}{ Uji Normalitas dengan Shapiro Wilk Test } & \multirow{3}{*}{ Uji Homogenitas } \\
\hline & \multicolumn{2}{|c|}{$\begin{array}{c}\text { Balance Strategy Exrcise } \\
\text { (KP 1) }\end{array}$} & \multicolumn{2}{|c|}{$\begin{array}{c}\text { Four Square Step } \\
\text { (KP 2) }\end{array}$} & \\
\hline & Rerata & $\mathbf{p}$ & Rerata & $\mathbf{p}$ & \\
\hline Sebelum & 45,56 & 0,104 & 46,33 & 0,128 & 0,251 \\
\hline Sesudah & 48,78 & 0,292 & 50,78 & 0,089 & 0,126 \\
\hline Selisih & 3,222 & 0 & 4,444 & 0,008 & 0,165 \\
\hline
\end{tabular}

Tabel 2 menunjukan hasil uji normalitas nilai $p$ untuk kelompok balance strategy exercise (KP 1) sebelum intervensi didapatkan nilai $p=0,104(p>0,05)$ dan setelah intervensi nilai $p=0,292(p>0,05)$. Pada kelompok four square step (KP 2) sebelum intervensi nilai $p=0,128(p>0,05)$ dan setelah intervensi nilai $p=0,089(p>0,05)$. Nilai selisih kelompok balance strategy exercise (KP 1) didapatkan nilai $p=0,000(p<0,05)$ dan selisih pada kelompok four square step (KP 2) diperoleh nilai $p=0,008(p<0,05)$.

Pada uji homogenitas menggunakan Levene's Test diperoleh nilai $p=0,251 \quad(p>0,05)$ untuk kedua kelompok sebelum intervensi dan sesudah intervensi nilai $p=0,126(p>0,05)$ sedangkan selisih diperoleh nilai $p=0,165(p>0,05)$ yang menunjukkan data sebelum, sesudah perlakuan dan selisih bersifat homogen.

Tabel 3. Hasil Peningkatan Keseimbangan Sebelum dan Sesudah Intervensi

\begin{tabular}{|c|c|c|c|c|}
\hline 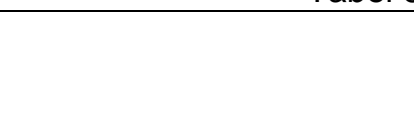 & $\begin{array}{c}\text { Rerata } \pm(\mathrm{SB}) \\
\begin{array}{c}\text { Skor BBS sebelum } \\
\text { intervensi }\end{array}\end{array}$ & $\begin{array}{c}\text { Rerata } \pm(\text { SB) } \\
\begin{array}{c}\text { Skor BBS setelah } \\
\text { intervensi }\end{array}\end{array}$ & $\begin{array}{c}\text { Beda } \\
\text { Rerata }\end{array}$ & $\mathbf{p}$ \\
\hline $\begin{array}{ll}\text { Balance } & \text { Strategy } \\
\text { Exercise } & \end{array}$ & $45,56 \pm(0,441)$ & $48,78 \pm(3,768)$ & 3,222 & 0 \\
\hline Four Squre Step & $46,33 \pm(0,726)$ & $50,78 \pm(2,728)$ & 4,444 & 0 \\
\hline
\end{tabular}

Tabel 3 menunjukan hasil uji beda rerata peningkatan keseimbangan dinamis dengan paired sample $t$-test sebelum dan sesudah intervensi pada kelompok balance strategy exercise (KP 1) dengan nilai $p=0,000(p<0,05)$ yang berarti bahwa terdapat perbedaan bermakna pada peningkatan nilai keseimbangan dinamis sebelum dan sesudah pelatihan balance strategy exercise pada lansia di Kelurahan Tonja.

Pengujian hipotesis sebelum dan sesudah intervensi pada kelompok four square step (KP 2) diperoleh nilai $p=0,000(p<0,05)$ yang berarti adanya perbedaan bermakna pada nilai rerata peningkatan keseimbangan dinamis sebelum dan sesudah intervensi four square step pada lansia di Kelurahan Tonja.

Tabel 4. Hasil Selisih Peningkatan Keseimbangan Dinamis Sebelum dan Sesudah Intervensi

\begin{tabular}{cccc}
\hline & Rerata $\pm($ SB) & Rerata $\pm($ SB) & \multirow{2}{*}{ P } \\
\cline { 2 - 3 } & Skor BBS & Skor BBS & \\
\hline Selisih & $3,22 \pm(0,500)$ & $4,44 \pm(0,726)$ & 0,001 \\
Persentase (\%) & $7,06 \%$ & $9,58 \%$ &
\end{tabular}

Tabel 4 menunjukan hasil beda selisih rerata peningkatan keseimbangan dinamis menggunakan uji Mann Whitney U-test dan didapatkan nilai $p=0,001 \quad(p<0,05)$ pada selisih sebelum dan sesudah perlakuan. Hasil ini menunjukkan bahwa ada perbedaan yang bermakna pada kedua kelompok perlakuan. Sedangkan hasil persentase peningkatan keseimbangan dinamis pada kelompok perlakuan 1 sebesar $7,06 \%$ dan persentase kelompok 2 sebesar $9,58 \%$. 


\section{DISKUSI}

Hasil Mann Whitney U-test untuk menguji perbedaan hasil peningkatan keseimbangan sebelum dan sesudah diberikan balance strategy exercise pada kelompok perlakuan 1 dan four square step pada kelompok perlakuan 2. Hasil analisis pada kelompok balance strategy exercise, didapatkan nilai rerata selisih adalah 3,222 (SB 0,500). Pada kelompok four square step didapatkan nilai rerata selisih adalah 4,444 (SB 0,726). Nilai probabilitas pada selisih kedua kelompok yaitu, $p=0,001 \quad(p<0,05)$. Nilai probabilitas yang didapatkan pada perbandingan hasil selisih pada kedua kelompok menunjukkan adanya perbedaan pada peningkatan keseimbangan yang signifikan antara kelompok balance strategy exercise (KP 1) dan kelompok four square step (KP 2), dimana pemberian four square step pada kelompok perlakuan 2 dapat lebih meningkatkan keseimbangan dibandingkan kelompok perlakuan 1 yang diberikan balance strategy exercise.

Pelatihan balance strategy exercise dan pelatihan four square step memiliki kesamaan yaitu, meningkatnya keseimbangan pada lansia dengan teknik mempertahankan stabilisasi, mengaktifkan sistem umpan balik pada strategi gerakan,. Pelatihan four square step mempunyai kelebihan yang lebih unggul dalam meningkatkan keseimbangan sehingga menjadikan pelatihan ini lebih efektif daripada balance strategy exercise.

Penelitian yang dilakukan oleh Duncan, dkk menyatakan pelatihan four square step ini membentuk sistem integrasi dan mengaktifkan sistem umpan balik pada gerakan dengan respon postural otomatis, mengaktifkan sistem gerakan volunter, respon postural otomatis. ${ }^{15}$ Guyton \& Hall menyatakan sistem vestibuloserebelum berguna untuk kontraksi otot agonis dan antagonis pada saat posisi tubuh berubah cepat. Pada pelatihan four squre step dapat memunculkan vestibuloserebelum yang berperan menghitung kecepatan gerakan dan arah selama beberapa milidetik yang akan datang. ${ }^{16}$

Didukung oleh penelitian yang dilakukan Tubero dkk menyatakan bahwa saat diaturnya keseimbangan diperkirakan bahwa informasi yang berasal dari bagian tepi tubuh maupun apparatus vestibular digunakan oleh sirkuit umpan balik yang berguna menyediakan koreksi pada sinyal motorik. Koreksi ini mengaktifkan umpan balik untuk mengkoreksi sikap dalam menjaga keseimbangan pada saat gerakan yang cepat, serta perubahan arah gerakan.$^{17}$

Shigematsu, dkk menyatakan bahwa selain pernyataan diatas pelatihan ini dapat meningkatkan kekuatan paha dan keseimbangan karena gerakan ini dapat dipastikan otot-otot tetap aktif sepanjang fase konsentrik dan menjaga kontrol tubuh, latihan ini dapat diasumsikan untuk meningkatkan fungsi-fungsi saraf dengan mengurangi respon interval waktu antara stimulus dengan respon yang diharapkan, efektif memunculkan reaksi postural, dan meningkatkan interpretasi pada informasi sensorik. Selain itu, langkah maju, mundur, kanan dan kiri selama latihan menyebabkan aktivasi yang lebih baik dari sinergis dan agonis kaki otot. Oleh karena itu, dapat meningkatkan banyak aspek fungsional kebugaran ekstremitas bawah. ${ }^{18}$

\section{SIMPULAN}

Maka dapat disimpulkan pelatihan four square step tiga kali dalam satu minggu selama lima minggu lebih efektif meningkatkan keseimbangan dinamis daripada pelatihan balance strategy exercise pada lansia di Kelurahan Tonja.

\section{SARAN}

Saran yang dapat diberikan yaitu pelatihan four square step dan balance strategy exercise dapat dijadikan salah satu pilihan terbaik tindakan fisioterapi dalam meningkatkan keseimbangan dinamis pada lansia dan dapat dilakukan dengan teratur. Selain itu, diharapkan untuk peneliti selanjutnya agar dapat mengembangkan penelitian lanjutan dengan membandingkan metode berbeda yang dapat meningkatkan keseimbangan dinamis pada lansia.

\section{DAFTAR PUSTAKA}

1. Efendi,F., Makhfudli. Keperawatan Kesehatan Komunitas Teori dan Praktik dalam Keperawatan. Jakarta: Salemba Medika. 2009

2. Runge, M., Rehfeld, G., \& Resnick, E. Balance Training and Exercise in Geriatric Patients. Journal Musculoskeletal Neuron Interaction. 1: 61-65. 2000

3. Farabi, A. Hubungan Tes "Time Up and Go" dengan Frekuensi Jatuh Pasien Lanjut Usia. Skripsi, Universitas Diponegoro, Semarang. 2007

4. Kusnanto., Indrawati, R., Mufidah, N. Peningkatan Stabilisasi Postural Pada Lansia Melalui Balance Exercise. Media Ners. 1: 49-65. 2007

5. Darmojo, B. Geriatri (IImu Kesehatan Usia Lanjut). Jakarta: Balai Penerbit FKUI. 2010

6. Meylisa, A. Pengaruh Balance Exercise Terhadap Peningkatan Status Keseimbangan Fungsional Pada Wanita Di Posyandu Lansia Ngadisono Kadipiro Surakarta. Skripsi, Universitas Muhammadiyah, Surakarta. 2012

7. Yuliana, S. Pelatihan Kombinasi Core Stability Exercise dan Ankle Strategy Exercise Tidak Lebih Meningkatkan dari Core Stability Exercise untuk Keseimbangan Statis pada Mahasiswa S1 Fisioterapi Stikes 'Aisyiyah Yogyakarta. Tesis, Universitas Udayana, Denpasar. 2014

8. Kloos, A. D \& Heiss, D. G. 2007. Exercise for Impaired Balance. Kisner, C \& Colby, L. A. Therapeutic Exercise edisi ke-5. Philadelphia. 2007

9. Masitoh, I. Pengaruh Balance Exercise Terhadap Keseimbangan Postural Pada Lanjut Usia Di Posyandu Abadi Sembilan Gonilan Sukoharjo. Skripsi, Universitas Muhammadiyah, Surakarta. 2013

10. Gunarto, S. Pengaruh Latihan Four Square Step Terhadap Keseimbangan Pada Lanjut Usia. Tesis, Universitas Indonesia, Jakarta. 2005

11. Dite, W. Temple, V. A. A clinical test of stepping and change of direction to identify multiple falling older adults. Archives of Physical Medicine and Rehabilitaton. 83: p 1566-1571. 2002 
12. Whitney, S. L., Marchetti, G. F., Morriset, L. O., Sparto, P. J. The reliability, validity and klasification of the Four Square Step Test for people with balance deficits secondary to a vestibular disorder. Archives of Physical Medicine and Rehabilitaton. 88: p 99-104. 2007

13. Neuls, P. Usefulness of the Berg Balance Scale to Predict Falls in the Elderly. APTA: Journal of Geriatric Physical Therapy. 34: p $3-10.2011$

14. Duncan, R. P., \& Earhart, G. M. Four Square Step Test Performance in People with Parkinson Disease. Journal of Neurologic Physical Therapy. 37: 2-8. 2013

15. Guyton, A. C., \& Hall, J. E. Text book of Medical Physiology $11^{\text {th }}$ ed. Philadelphia: Elsevier Saunders. 2008

16. Túbero, G.S., Gobbi, S., Teixeira C.V.L,. Pereira, J.R., Shigematsu, R., Canonici, A.P. Effects of square stepping exercise in patients with sequel of cerebrovascular accident. Fisiotherapy Movement. 27(2): p 229-237. 2014

17. Shigematsu,R.,Okura,T.,Nakagaichi,M.,Tanaka,K.,Sakai,T.,Kitazumi, S., Rantanen,T. Square-Stepping Exercise and Fall Risk Factors in Older Adults: A Single-Blind, Randomized Controlled Trial. Journal of Gerontology. 63(1): p 76-82. 2008 